3. Biron, K.K. et al. Proc. natn. Acad. Sci. U.S.A. 82, 2473 2477 (1985).

4. Daggett, S.G., Gruys, K.J. \& Schuster, S.M. J. biol. Chem 260, 6213-6218 (1985).

5. Ramos, F. \& Wiame, J.M. Molec. gen. Genet. 200, 291-294 (1985).

6. Huang, D.P., Cote, G.J., Massari, R.J. \& Chiu, J.F. Nucleic Acids Res. 13, 3873-3890 (1985).

7. Inman, R. B. Biochim. biophys. Acta 783, 205-215 (1985)

\section{Gamma-ray spectrum of Chernobyl fallout}

SIR-The activity in Oxfordshire due to the plume of radioactive material released from the Chernobyl reactor reached a peak on 2 May'. $^{1}$ On 8 May we examined the 'Polyfoam' air filters routinely used in our laboratory air supply system and monitored a small but distinct amount of $\beta$ - and $\gamma$-radiation activity. We have measured the $\gamma$-ray energy spectrum from the filters using a high-efficiency $(40 \%)$ germanium detector, shielded from room background.

Figure 1 shows the complex $\gamma$-ray spectrum from the filters. The background is due to Compton-scattered $\gamma$ rays, which do not deposit their full energy in the detector. An analysis of the fullenergy peaks yields a definite identification of 16 radioisotopes, with a further three (weaker) tentatively identified radioisotopes. The activity of each radioisotope is categorized as strong or weak in Table 1. The relative activities for the most prominent isotopes vary significantly from those deduced by Fry et al. ${ }^{\prime}$, which serves to emphasise that these coarse filters were not designed to collect fallout products. The measured activity of $\sim 2,000 \mathrm{~Bq} \mathrm{~m}^{-2}$ of ${ }^{131} \mathrm{I}$ on each $0.1 \mathrm{~m}^{2}$ filter suggests that $\sim 1 \%$ of the local iodine activity ${ }^{1}$ was deposited by the air flow of

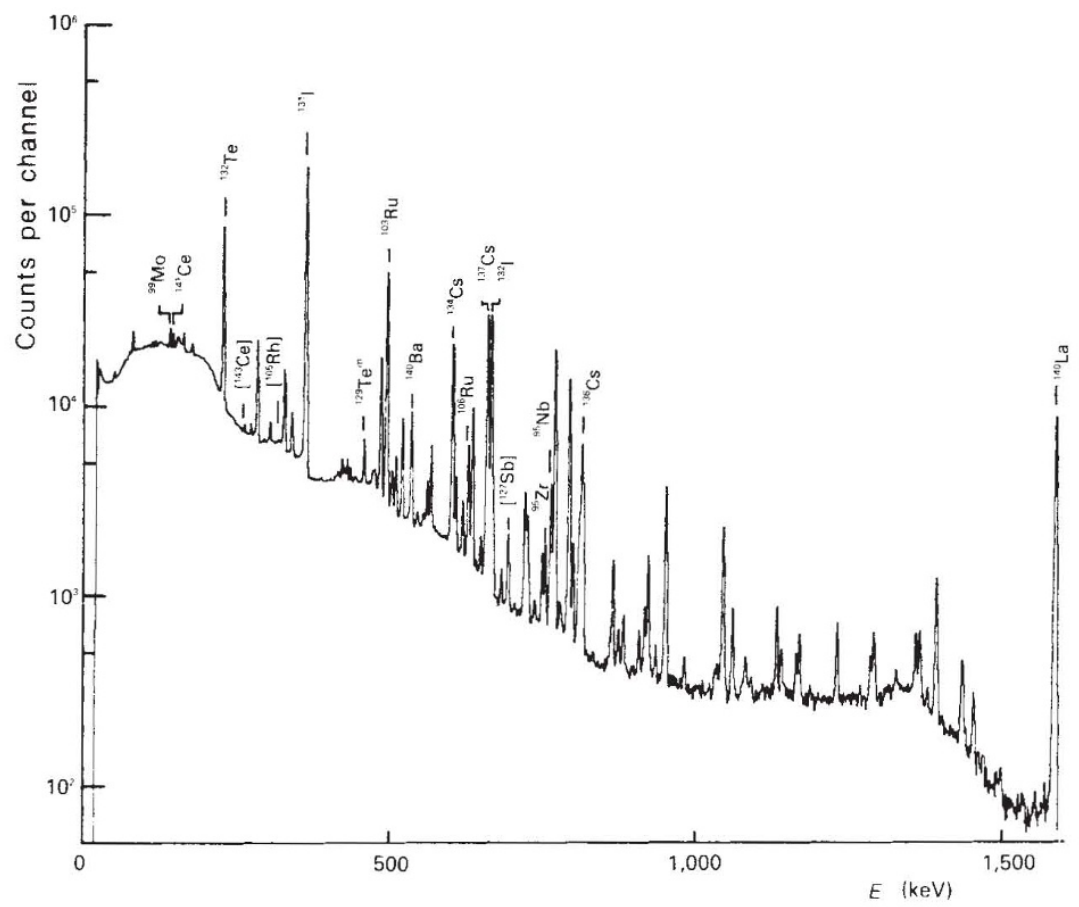

Fig. 1 Part of the $\gamma$-ray spectrum obtained with a $\mathrm{Ge}(\mathrm{Li})$ detector from a typical air filter. The strongest identified peak of each radioisotope is labelled.
Table 1 Relative $\gamma$-ray activities of radioisotopes measured in laboratory air filters

\begin{tabular}{|c|c|c|}
\hline Isotope & $\begin{array}{l}\text { Relative } \\
\text { activity* }\end{array}$ & Half-life \\
\hline${ }^{131} \mathrm{I}$ & $\mathrm{S}$ & $8 \mathrm{~d} \dagger$ \\
\hline${ }^{1.37} \mathrm{Cs}$ & $\mathrm{S}$ & $30 \mathrm{yr}$ \\
\hline${ }^{132} \mathrm{Te}$ & $\mathrm{S}$ & $3 \mathrm{~d}$ \\
\hline${ }^{132} \mathrm{I}$ & S & $2 \mathrm{~h}$ \\
\hline${ }^{103} \mathrm{Ru}$ & S & $39 \mathrm{~d}$ \\
\hline${ }^{134} \mathrm{Cs}$ & $S$ & $32 \mathrm{yr}$ \\
\hline${ }^{106} \mathrm{Ru}$ & $\mathrm{S}$ & $367 \mathrm{~d}$ \\
\hline${ }^{140} \mathrm{Ba}-{ }^{140} \mathrm{La}$ & $\mathrm{S}$ & $13 \mathrm{~d}-40 \mathrm{~h}$ \\
\hline${ }^{136} \mathrm{Cs}$ & W & $13 \mathrm{~d}$ \\
\hline${ }^{95} \mathrm{Zr}-{ }^{95} \mathrm{Nb}$ & W & $64-35 d$ \\
\hline${ }^{141} \mathrm{Ce}$ & W & $33 \mathrm{~d}$ \\
\hline${ }^{99} \mathrm{Mo}$ & W & $3 \mathrm{~d}$ \\
\hline${ }^{144} \mathrm{Ce}$ & W & $284 \mathrm{~d}$ \\
\hline${ }^{129} \mathrm{Te}^{m}$ & W & $33 \mathrm{~d}$ \\
\hline$\left[{ }^{127} \mathrm{Sb}\right]$ & [W] & $4 d$ \\
\hline [105 Rh] & [W] & $1.5 \mathrm{~d}$ \\
\hline$\left[{ }^{143} \mathrm{Ce}\right]$ & [W] & $1.5 \mathrm{~d}$ \\
\hline
\end{tabular}

*Identified radioisotopes are listed in order of activity. Isotopes with activities greater than $10 \%$ that of ${ }^{131} \mathrm{I}$ are labelled strong (S) and those with activities less than $5 \%$ are labelled weak (W). $†$ Days.

\section{$2 \times 10^{4} \mathrm{~m}^{3}$ per day.}

All of the identified radioisotopes are ${ }^{235} \mathrm{U}$ fission decay products. The criteria for observing a particular fission product in such a simple $\gamma$-decay experiment are: (1) the feeding mass chain should have a lifetime $\geqslant 1$ day and $\leqslant 500 \mathrm{yr}$; (2) the fission yield should be $\geqslant 0.5 \%$ for the mass chain; (3) the $\beta$-decays should significantly populate excited nuclear states which subsequently $\gamma$-decay. Using these simple criteria, we find that all of the expected mass chains are accounted for,

\section{p} $\left(r / r_{0}\right)^{-1.8}$, where $r_{0}=5(1+z)^{-1} h^{-1} \mathrm{Mpc}, h=$ the Hubble constant $H_{0} / 100 \mathrm{~km} \mathrm{~s}^{-1} \mathrm{Mpc}^{-1}$ and the cosmological density parameter $\Omega_{0}=1$. The probability associated with this excess for a given quasar to have a companion within angle $\theta$ brighter than magnitude $m$ is then

$$
\begin{aligned}
P_{c}(\theta, m, z)= & 2 \pi(1+z)^{3} \int_{0}^{\infty \theta} \mathrm{d} b b \times \\
& \times \int_{-\infty}^{\times} \mathrm{d} l \Phi \xi\left[\left(b^{2}+F^{2}\right)^{1 / 2}\right]
\end{aligned}
$$

where $D(z)$ is the angular diameter distance of the quasar, and $\Phi(L, z)$ is the integral luminosity function for quasars with luminosity $L(m, z)$. Now, $\Phi(L, z)=(\mathrm{d} n / \mathrm{d} z) / D^{2}(1+z)^{1 / 2}$ (ref. 8) and observations ${ }^{4}$ indicate that for $0.5<z<2$, quasars of a given magnitude are uniformly distributed in redshift with $\mathrm{d} n / \mathrm{d} z \simeq 0.5 n$. Substitution in equation (1) then gives $P_{c}(\theta, m, z)=38(1+z)(1+z-$ 1) $\theta^{3} \xi(\theta D) \mathrm{d} n / \mathrm{d} z$ for $D \theta \leqslant 2 r_{0}$, where $n$ is per steradian and $\theta$ in radians. Numerically, $P_{\mathrm{c}} \sim 2 \times 10^{-4}$. 